"Monetary policy decision-making when information search is costly"

\begin{tabular}{|c|c|c|}
\hline AUTHORS & $\begin{array}{l}\text { Alexander Jung } \\
\text { Francesco Paolo Mongelli }\end{array}$ & \\
\hline ARTICLE INFO & \multicolumn{2}{|c|}{$\begin{array}{l}\text { Alexander Jung and Francesco Paolo Mongelli (2016). Monetary policy decision- } \\
\text { making when information search is costly. Banks and Bank Systems, 11(1), 15- } \\
\text { 22. doi:10.21511/bbs.11(1).2016.02 }\end{array}$} \\
\hline DOI & \multicolumn{2}{|c|}{ http://dx.doi.org/10.21511/bbs.11(1).2016.02 } \\
\hline RELEASED ON & \multicolumn{2}{|l|}{ Monday, 25 April 2016} \\
\hline JOURNAL & \multicolumn{2}{|l|}{ "Banks and Bank Systems" } \\
\hline FOUNDER & \multicolumn{2}{|c|}{ LLC "Consulting Publishing Company "Business Perspectives" } \\
\hline \multirow{3}{*}{ NUMBER OF REFERENCES } & & $\begin{array}{l}= \pm= \\
= \pm=\end{array}$ \\
\hline & NUMBER OF FIGURES & NUMBER OF TABLES \\
\hline & 0 & 0 \\
\hline
\end{tabular}

(C) The author(s) 2022. This publication is an open access article. 
Alexander Jung (Germany), Francesco Paolo Mongelli (Germany)

\title{
Monetary policy decision-making when information search is costly
}

\begin{abstract}
This paper explores monetary policy decision-making within an insurance model with expected utility-maximizing policy-makers. The authors consider that policy-makers are different in terms of their backgrounds, experience and skills and they may disagree on the appropriate policy response. In a monetary policy committee, they share information and decide on interest rates by means of an agreed voting rule. The authors show that, in the presence of risk and search costs, it would be optimal for policy-makers to fully insure against the expected loss from a potential policy error. Whether a monetary policy committee sufficiently hedges against this risk will depend on several factors such as the skills of policy-makers, the distribution of members' beliefs, and the committee's (statutory) voting rule, but also on other factors not captured by the model.
\end{abstract}

Keywords: monetary policy committee, analysis of collective decision-making, search costs, voting behavior.

JEL Classification: D72, D81, D83, E58.

\section{Introduction}

Monetary policy-makers face various types of uncertainty. These uncertainties are exacerbated during episodes of a financial crisis. Policy-makers face multiple types of uncertainty about the current and future state of the economy, the structure of the economy, and the strategic interactions between economic agents. The literature suggests that in the presence of multiple uncertainties, making committees in charge of monetary policy decisions is beneficial (see, e.g., Blinder, 2004). Importantly, the advantage of a monetary policy committee is that, its policy-makers may benefit from a fruitful group interaction, which will force the committee to consider a wider and broader range of possible future outcomes.

The real-time assessment of the monetary policy stance, and the monetary policy response to shocks hitting the economy are affected by multiple sources of uncertainty, which cannot be all captured in a single model. First, policy-makers face uncertainty about the state of the economy which concerns various forms of data and model uncertainty. Second, there could be also uncertainty about how the economy may be working, and evolving over time (uncertainty about the structure of the economy). Another source of uncertainty is behavioral and concerns the dynamic interaction between a central bank and private agents and, possibly, other policy-makers. This point got special prominence during the financial crisis. When structural relationships change, the uncertainty about the monetary policy transmission mechanism may be higher. Though, when taking monetary policy decisions, policy-makers follow their beliefs about the

(c) Alexander Jung, Francesco Paolo Mongelli, 2016.

Alexander Jung, Senior Economist at the European Central Bank, Germany. Francesco Paolo Mongelli, Senior Adviser at the European Central Bank, Honorary Professor at the Frankfurt Goethe University, Germany.

The views expressed in this paper are our own and do not reflect those of the Eurosystem. We remain responsible for any errors or omissions. working of the economy and these beliefs are normally based on validity of existing relationships. Hence, in times of changing relationships (like during a financial crisis), there is the risk that policy-makers recognize these changes at a rather late stage. Moreover, the Condorcet jury theorem suggests that larger committees do a better job in making decisions under uncertaintly than smaller committees (see Austen-Smith and Banks, 1996). The sources of uncertainty may be the same regardless of the size of a monetary policy committee, but they may be specific to the monetary policy regime that is chosen, as well as to other factors.

The aim of this paper is to analyze whether monetary policy-makers can hedge themselves against the risk of policy error in the presence of Knightian uncertainty. We show that, in the presence of search costs, it would be optimal for policy-makers to fully insure against the expected loss from a potential policy error. But, heterogeneous beliefs about the future state of the economy and voting rules may lead to suboptimal hedging strategies with higher risk of policy errors.

The paper is organized as follows. Section 1 recalls some shortcomings of the traditional risk management approach to monetary policy. Section 2 presents a stylized model and analyses to what extent the presence of search costs influences the outcome of the decision-making process under uncertainty. Section 3 illustrates the potential impact of alternative (statutory) voting rules on the hedging behavior of a monetary policy committee under uncertainty. Final Section concludes.

\section{Limitations of the risk-management approach}

In Brainard's (1967) model, policy-makers should aim for attenuation and gradualism in the conduct of policy under uncertainty. He proposed an analogy between a monetary policy-maker and a risk manager. Monetary policy decision-making can be characterized as an 
ongoing cost-benefit analysis to cope with risk and uncertainty. Former Fed Chairman Greenspan (2004) subscribed to this notion of policy-making and stressed that monetary policy involves: "understanding as much as possible the many sources of risk and uncertainties that policy-makers face, quantifying those risks when possible, and assessing the costs associated with each of the risks".

Today, the monetary policy process of most central banks in developed countries is guided by a risk management approach (RMA) to monetary policymaking. This can be illustrated, for example, by the increasing popularity of strategies focusing on the "risks to price stability" (e.g., various variants of the inflation targeting strategy). Because monetary policy works with a lag, and monetary policy decisions are taken in real time, the precise stance of the real economy is not fully known at the time of the policy meeting. In the RMA, the ability of policymakers to cope with data and model uncertainty and to identify the best possible policy response, importantly, depends on the quality of forecasting and of scenario analysis. This is because cost-benefit analyses of policy alternatives are based on forecasts that are generated by econometric models run by experts ${ }^{1}$.

The risk management approach is very intuitive, though it has some limitations in theory and practice. First, the approach does not explicitly model the costs of information search. Second, policymakers may be more averse to deflationary than to inflationary shocks so that the underlying loss function may not be symmetric (see Kilian and Manganelli, 2008). Third, as documented by various authors (e.g., Kenny and Morgan, 2011), in specific episodes of a financial crisis the predictive failure of macroeconomic tools and expert judgement widely shared by institutional and private forecasters alike is present. Fourth, as suggested by Taleb (2007), decision-makers are mainly concerned about the costs of possible policy mistakes. They worry less about statistical distributions of risks in their assessments, i.e., they tend to ignore those risks that have a small probability and cannot be quantified with any confidence (tail risks). An important reason for this behavior is that the monetary policy decision-making process entails substantial costs. Hence, policy-makers have an incentive to economize on their efforts and to focus on a limited number of measurable risks. Fifth, the higher the degree of uncertainty surrounding "model-based analysis", the more policy-makers may deviate from the risk management approach and, instead, rely on their heuristics (i.e.,

\footnotetext{
${ }^{1}$ See Bank for International Settlements (2009) for an international comparison.
}

their whole body of knowledge, experience and beliefs) and apply judgement. It will lead to a greater dispersion of probabilities assigned by policymakers to the risks of certain events, even though they share all available information among them. From central bankers' communications, it is evident that during crisis events policy-makers tend to base their monetary policy decisions more on their individual judgement and heuristics than ot herwise ${ }^{2}$.

\section{A model of decision-making with search costs}

In this Section, we introduce a stylized model of the monetary policy decision-making process that takes into account search costs. We assume that policymakers pursue only one domestic policy objective (i.e., a price stability objective). The actors of the model are expected utility-maximizing policymakers, but their skills may vary (see Berk and Bierut, 2009).

2.1. The role of search costs. Policy-makers take decisions using available information and exercising judgement. There is uncertainty about the future state of the economy, and, thus, alternative outcomes are conceivable. Before deciding on interest rates, policy-makers are expected to prepare for the policy meetings and to share information with their peers. They face search costs when gathering information on the current and future state of the economy. This aspect is neglected in most models on monetary policy decision-making. In the presence of such costs, policy-makers have to decide how much effort their staff should make to provide them with relevant information. Gathering of relevant information can help to improve the quality of the policy decision, given uncertainty. For instance, such efforts may reduce (forecast) uncertainty and thereby contribute to increasing the robustness of the decision. In this sense, policy-makers can, by expanding their information gathering activities, hedge against the risk of policy error. The negative impact of a policy error may still materialize, but the resulting consequences can be mitigated by appropriate monetary policy decisions.

In order to examine what policy-makers should do in the presence of increased uncertainties, we refer to a variant of the (optimal) insurance model proposed by Arnott and Stiglitz (1988). We assume that policy-makers can be modelled as expected utility-maximizing agents. There is uncertainty about the future state of the economy and policymakers take their decisions as risk-managers who have certain ideas of how likely it is that a policy error happens, given available information. An ana-

${ }^{2}$ Examples are the lost decade of Japan (see Krugman, 1998), and the global financial crisis of 2007 to 2009 (see Bernanke, 2010). 
logy to the insurance model can be drawn with some modifications. Policy-makers are especially concerned about the possibility of policy error, which could have adverse consequences for the fulfilment of the central bank's objective. With some probability, such policy error will happen, but this probability is not known to policy-makers in real-time (or ex ante). The question is: what would expected utility-maximizing policy-makers do to cope with this situation? In the analysis of monetary policy, decision-making information search can be thought to be a production technology that helps to hedge against the risk of policy errors in the following sense: collecting, interpreting, and sharing of relevant information can improve the robustness of monetary policy decisions. At the same time, information gathering entails costs which are usually neglected when analyzing the decision-making process. Information search allows policy-makers to hedge against the risk of policy error under incomplete information, since more (and better) information brings them closer to full information. It, thus, increases the likelihood for policy-makers to make the right choice.

In the presence of search costs, policy-makers will economize on their efforts, and, also, exert judgement. Hence, they have an incentive to use an information set that is less comprehensive than full information. In this paper, we assume that information gathering activities by policy-makers can be described by a technology which follows Gossen's first law of diminishing marginal returns. Consistent with the notion of informationally efficient markets (see Fama, 1970), policy-makers can increase their overall utility from information search until they have reached full information, but not beyond that point. ${ }^{3}$ In the next subsection, we derive the optimal hedging decision of expected utility-maximizing policy-makers in the presence of search costs. Then, we discuss whether under increased uncertainty about the probability of a policy error, committees with heterogeneous beliefs and individual decisionmakers react differently, and whether it can be expected that they make robust decisions.

\subsection{Optimal decisions under Knightian uncer-}

tainty. There are various ways to account for uncertainty in monetary policy decision-making ${ }^{4}$. In line with the literature, we assume that two alternative,

\footnotetext{
${ }^{3}$ In what follows, we abstract from agreement costs, and ignore strategic behavior and agenda-setting techniques within the committee (see Berk and Bierut, 2005).

${ }^{4}$ In this respect, Wieland (2006) refers to simple Taylor rules and suggests that uncertainty on the relationship between inflation and unemployment matters, particularly, for policy-makers of the interaction may also take the form of games between monetary and fiscal policy-makers (see Adam and Billi, 2006; Gerling, Grüner, Kiel and Schulte, 2005).
}

well-defined, future states of the economy can occur with some probability. Yet, policy-makers are unable to form exact probability judgements about their occurrence ${ }^{5}$ :

- in the first state, an unanticipated inflationary (or deflationary) shock hits the economy and surprises policy-makers. The policy error results in a loss in terms of expected utility. The loss can be mitigated though. In anticipation of the shock, policy-makers can increase their information gathering efforts, thereby identifying a policy response that attenuates the negative consequences of the shock. This hedging strategy against a policy error is thought to compensate for the associated loss. Still, some of the costs of the policy error may be unavoidable and have to be borne; and

- in the second state of the economy, there is no unanticipated inflationary (or deflationary) shock, policy-makers are well-informed and make the right decision. In this state, only search costs for information gathering will reduce the net payoff.

We also assume that policy-makers are risk averse and that they maximize the net expected value of their choices, given these two alternative states of the economy. With probability $\alpha$, the value of the outcome is $x_{1}$ and with probability $(1-\alpha)$ the outcome is $x_{2}$ :

$$
\operatorname{Max} \alpha u\left(x_{1}\right)+(1-\alpha) u\left(x_{2}\right) \text {. }
$$

Assume further that policy-makers have an identical utility function (1), and an identical search cost function $c$. For the monetary policy committee, it is assumed that available information is fully shared among the members (i.e., there is no strategic behavior and members are fully cooperative). Policymakers receive a positive gross gain $x$ from taking a decision (e.g., in terms of credibility). Gains have to be balanced with search costs $c$ for information gathering, and with the loss $d$ in case policy error happens ${ }^{6}$.

We define a multiplier $\Phi>0$ as a measure of the effectiveness of policy-makers' information gather-

\footnotetext{
${ }^{5}$ This assumption, which has been referred to in the literature as Knightian uncertainty, may be quite restrictive in this context for the following reasons. First, for a host of shocks, it may, indeed, be possible for monetary policy-makers to influence the probability of policy outcomes. Second, policy-makers could improve their decisions by means of Bayesian learning. Third, in the presence of Knightian uncertainty, policy-makers may no longer behave as expected utility-maximizers, but may adopt other strategies such as max min expected utility maximization or robust control methods.

${ }^{6}$ The model abstracts from the possibility that false information could be misleading in the policy process. A way to address this point formally would be to specify a screening device which allows policy-makers to distinguish between "true" and "false" information.
} 
ing efforts. It expresses the overall returns from information gathering as a multiple of search costs. Information search is thought to provide policymakers with a (positive) payoff $\Phi c$, which may partly or fully offset the loss in case a policy error occurs ${ }^{7}$.

The ratio $\frac{d}{\Phi}$ can be interpreted as hedging ratio. Policy-makers are assumed to maximize the net expected value from the two alternative outcomes such as (see Varian, 1992):

$\max \alpha u\left(x-d-c+\Phi_{c}\right)+(1-\alpha) u(x-c)$,

where $0<\alpha<1$ is the probability that a policy error happens. This probability of the unanticipated shock for the economy is exogenous to the model. In the beginning of the period, a decision has to be taken, and, in the end of the period, nature reveals the state of the world. Policy-makers cannot influence the probability distribution of the shocks, but by their decision they can only attenuate the response to the unanticipated inflationary shock (i.e., in part offset the loss). Moreover, we exclude the extreme cases where $\alpha$ is zero or unity, because both would imply that policy-makers know with certainty which state will materialize and they would receive the payoff from this state with certainty.

Maximization of expected utility with respect to search costs leads to:

$\frac{u^{\prime}\left(x-d+(\Phi-1) c^{*}\right)}{u^{\prime}\left(x-c^{*}\right)}=\frac{1-\alpha}{\alpha(\Phi-1)}$.

In order to solve the problem and to determine the optimal amount of information search effort $\mathrm{c}^{*}$, only efficient "hedging" strategies are considered. Policy-makers that are strictly risk averse (i.e., $u^{\prime}$ $(x)<0$ ) are indifferent between "buying insurance" and "exerting judgement", if the marginal utility from both states is identical. This condition is satisfied if the expected payoff from additional insurance is zero:

$$
\frac{(1-\alpha)}{\alpha(\Phi-1)}=1
$$

Under this condition, it is not possible for a policymaker to increase his/her (net) utility from information search. Taking (3) and (4) together, it can be

\footnotetext{
${ }^{7}$ Note that the introduction of exponential search costs and returns would complicate the analysis, but would not change the general results here.
}

shown that an efficient "hedging" strategy $\left(\Phi^{\max }\right)$ is just a function of the (exogenous) probability $\alpha^{8}$ :

$\Phi^{\max } \frac{1}{\alpha}$

Given that the probability of a policy error is in the range of $] 0 ; 1\left[, \Phi^{\max }\right.$ is always greater than unity. It will be higher (lower), the smaller (bigger) is the probability of a policy error. With $\Phi^{\max }>1$, policymakers always obtain net benefits from their investment in information search. Hence, the condition for the optimal investment in information search under an efficient hedging strategy under (3) and (5) is given by:

$c^{*} \frac{d}{\Phi^{\max }}=\alpha d$.

Hence, the model illustrates (see equation 6) that expected utility-maximizing policy-makers have an incentive to fully insure against the expected loss from a potential policy error. For strictly risk averse policy-makers, it would be rational to formulate a policy response by which the expected negative consequences of the unanticipated shock can be fully offset. The greater the probability of a policy error, the more insurance policy-makers should buy.

2.3. Heterogeneous skills of policy-makers. Heterogeneous information processing skills may influence policy-makers' hedging decision. The optimal hedging decision (see equation 6) also depends on the skills of policy-makers in information processing, as measured by the value of $\Phi$. Hence, for a given probability, policy-makers with a higher (lower) ratio of effectiveness in information processing (where $\Phi_{H}>\Phi>\Phi_{L}$ ) would need a lower (higher) investment in information search in order to hedge against the risk of policy error.

Figure 1 illustrates policy-makers' payoff from information search which increases with the amount of investment in information search. If the probability of a policy error was known with certainty, it would be optimal for a policy-maker or committee to invest the amount of search costs $c^{*}$, which would yield a corresponding payoff $\alpha d \Phi$. For a given probability $\alpha$ and a known loss $d$, the payoff from hedging depends only on the multiplier $\Phi$. Assume for the purpose of illustration, the information processing skills of a representative policymaker are given by $\Phi$. Moreover, the single policymaker and the policy committee would invest the optimal amount of search costs $c^{*}$. If the policy committee has a lower ratio of effectiveness $\left(\Phi_{L}<\right.$

\footnotetext{
${ }^{8}$ Note that the probability of a state to materialize is exogenous, so that the policy-maker can only influence the consequences of the unanticipated shock for the economy, but not the likelihood of its occurrence.
} 
$\Phi)$ than the single policy-maker, the resulting payoff from hedging $\left(\alpha d \Phi_{L}\right)$ would be smaller.

Hence, compared to the single policy-maker, the committees' hedging gain would be smaller. While they would invest much more in information search (as compared to the single policy-maker), they would buy sufficient insurance against the risk of policy error, but face higher costs. If, however, the policy committee has a higher ratio of effectiveness $\left(\Phi_{H}>\Phi\right)$ than the single policy-maker, the resulting payoff from hedging $\left(\alpha_{H} d \Phi\right)$ would exceed that of a single policy-maker. In sum, efficient policy committees can be expected to make robust policy deci- sions, but may face higher search costs than an individual policy-maker. At the same time, less efficient policy committees may expose themselves to a greater risk of policy error. The above analysis implies that the widespread notion, according to which policy committees are, generally, superior to single policy-makers, may not always hold. For instance, if, in the presence of uncertainty, the discussions in a policy committee are characterized by a low degree of effectiveness in information gathering, the single policy-maker will have it easier to make more robust monetary policy decisions than the committee.

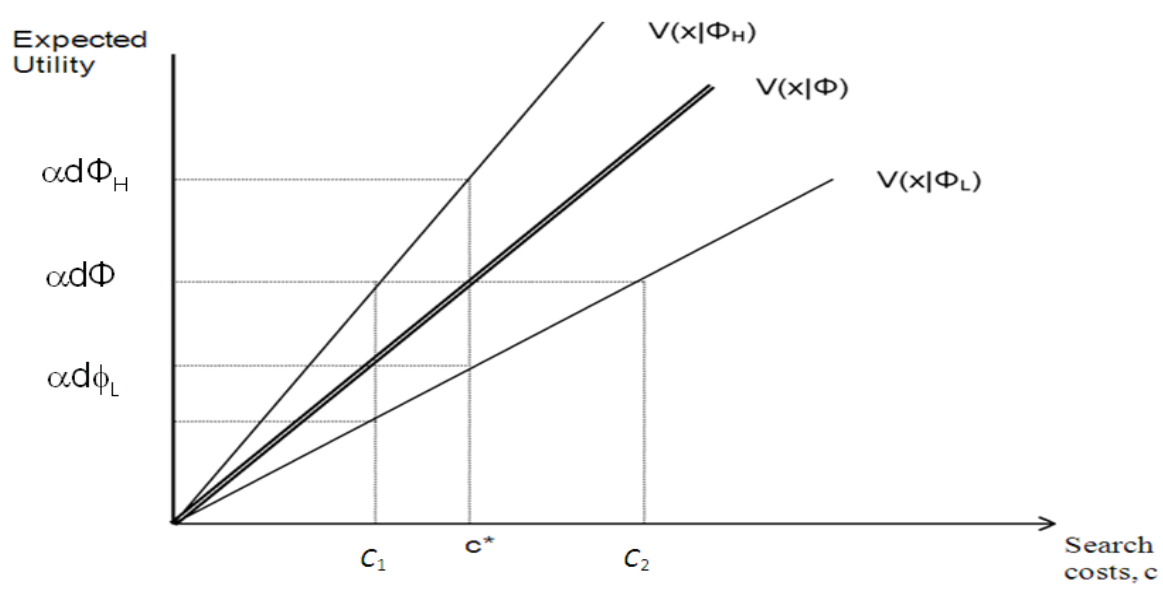

Fig. 3. Information search and gains from hedging

\section{Voting rules and heterogeneous beliefs}

In a monetary policy committee, agreement is sought by means of a (statutory) voting rule ${ }^{9}$. It must be respected by all members of the committee. The voting rule is an important tool for group decision-making. In the presence of disperse preferences and views across members, it would be, otherwise, very difficult and time-consuming to agree on a policy option. The voting rule is, therefore, also a way of dealing with uncertainties in monetary policy committees.

In order to examine what would be the influence of alternative voting rules on the outcome of group decision-making, we refer to our insurance model and assume that risk averse policy-makers try to form a common belief on the (unknown) probability $\alpha$ instead of voting on the interest rate, as in conventional models. In a monetary policy committee, there could be a continuum of diverse views on the true value of $\alpha$. We illustrate under what conditions the hedging behavior of policy-makers may be sensitive to the voting rule. In order to address the question, we compare the outcome of a committee decision under a specific voting

\footnotetext{
${ }^{9}$ The choice of a voting rule is part of the institutional setup of a committee. The voting rule is normally binding for a series of committee meetings. Therefore, it is often laid down in the statutes or rules of procedures of a central bank.
}

rule with a policy committee that averages votes (i.e., a representative policy-maker) ${ }^{10}$.

A voting rule has two main objectives. First, it provides a platform for discussing the "true" preferences of committee members on available policy options and assesses the extent of mutual agreement for a certain policy decision. Second, a voting rule helps to ensure that, at the end of the meeting, one of the policy alternatives is chosen (i.e., the outcome of the monetary policy process becomes decisive). Various advantages and disadvantages from different voting rules have been widely discussed in the literature (for a discussion, see Smidkova, 2003). Majority voting is widespread among committees, because it always provides an outcome, and most committee members would agree to it. The ease of agreement on decisions by majority voting has to be balanced with the costs in terms of potential policy error when a monetary policy decision is taken too "quickly". Most voting rules have the property that an individual voter in the committee whose preference will determine the

\footnotetext{
${ }^{10}$ In the literature, averaging is often discussed as a conceivable option for monetary policy committees, albeit less relevant in practice. Gerlach-Kristen (2004) shows that this rule may be relevant for our comparisons, because, under certain conditions, averaging of policymakers' votes ensures optimality.
} 
outcome of the policy decision can be identified (see second column of Table 1). In some instances, however, the outcome of the vote is a priori indeterminate (e.g., unanimity voting when views are heterogeneous).

Table 1. Outcome of the vote under alternative voting systems

\begin{tabular}{|c|c|c|}
\hline Votina rule & "Desisive" voter & Outcome \\
\hline Averaging & Mean voter, $A$ & $y_{A}=\frac{1}{n} \sum_{j=1}^{n} y_{j}$ \\
\hline \multirow[t]{2}{*}{$\begin{array}{l}\text { Majority } \\
\text { voting }\end{array}$} & Median voter, $M$ & $\begin{array}{l}y_{M}=y_{\frac{n+1}{2}} \text {, if } n \text { is uneven } \\
y_{M}=y_{\frac{n}{2}} \text { if } n \text { is even }\end{array}$ \\
\hline & Chairman, $\mathrm{Ch}$ & $y_{C h}$, if he/she has a casting vote \\
\hline $\begin{array}{l}\text { Qualified } \\
\text { majority } \\
\text { voting }\end{array}$ & $\begin{array}{l}\text { "Quorum" voter, } \\
Q\end{array}$ & $\begin{array}{l}y_{Q}=y_{\frac{n+1}{2}+q} \text { with quorum } \\
q<\frac{n-1}{2} \text { if } n \text { is uneven } \\
y_{Q}=y_{\frac{n}{2}+q} \text { with quorum } \\
q<\frac{n}{2} \text { if } n \text { is even }\end{array}$ \\
\hline Unanimity & $\begin{array}{l}\text { Each voter, } 1 \ldots \\
n\end{array}$ & $y_{u}=y_{1}=\ldots=y_{\prime \prime}$ \\
\hline
\end{tabular}

Notes: $A$ : mean; $C h$ : Chairman; $M$ : median; $Q$ : quorum; $U$ : unanimity. 1) Note that in committees with a symmetric distribution of preferences around the mean (and in committees with only three members), the mean voter and the median voter would be identical.

Under uncertainty, what is the impact of alternative voting rules on the robustness of monetary policy decisions by a committee? Could it change the outcome in a way that a committee systematically neglects important information that is relevant for the decision-making process? In other terms, could an individual policy-maker make more robust monetary policy decisions than a committee that agrees by means of a specific voting rule? Voting on interest rates in committees often works as follows: at the policy meeting, the Chairman of the committee moderates an exchange of information and views among members, on the basis of a pre-set agenda, so as to develop a consensus on the policy issue. Despite a diversity of views among members on which policy option to choose, by the end of the meeting at the latest, they will have to agree on a joint decision by means of a vote. While, during the deliberations, committee members may signal their assessments on the policy alternatives, when it comes to voting, each member has to provide a firm preference. In this respect, an agenda by which committee members vote at the end of the meeting ensures that members share information, and that their final vote is based on all information available and shared at the time of a meeting (see Berk and Bierut, 2005).

Now, we make the following experiment. In the absence of knowledge of the true probability $\alpha$, policymakers follow the principle of indifference and choose an initial value $\alpha=0.5$ (see Figure 2, LHS). Then, a shock occurs, which could have positive or negative consequences for the inflation outlook. Increased uncertainty implies that policy-makers of a committee will have different beliefs about the likelihood of a policy error. Committee members are expected to form a common view about $\alpha$. At the policy meeting, they may exchange their views and, at the end, the Chairman holds a vote on the probability $\alpha$. All members know that if the vote is not "decisive", this will be counted as a confirmation of the initial assessment (i.e., $\alpha=0.5$ ). Without such a rule, the outcome of the vote could be indeterminate, e.g., under the unanimity rule when there are heterogeneous beliefs.

As is well known from the literature on voting (see Tidemann, 2006), in this ballot, the representative policy-maker would always choose the mean of the individual probabilities of the committee members. The median would determine the outcome for a monetary policy committee under majority voting ${ }^{11}$. Under qualified majority voting, the outcome would be similar to majority voting, if one group gains the quorum, but, if none of the two groups has enough members to gain the quorum, the outcome of consensus voting would be the status quo. Under the unanimity rule, each member's vote could become "decisive" because of his/her veto power in case of dissent. Therefore, this rule has a strong tendency to confirm the initial assessment.

Figure 2 (LHS) illustrates that with a (mean)symmetric probability distribution of policy-makers' beliefs (in our thought experiment), both a representative policy-maker and a committee under alternative voting rules would choose the initial value ( $\alpha=0.5$ ). In this case, when a shock occurs, the committee will

\footnotetext{
${ }^{11}$ Note that with an uneven number of members the rule is always decisive, but for an even number of members there may be ties. In order to avoid ties, most monetary policy committees either comprise of an uneven number of members or the Chairman is given a casting vote.
} 
stick to its prior and the voting system will not influence the outcome. Next, we turn to an asymmetric probability distribution (Figure 2, RHS). In the presence of the shock, several members will revise their priors towards higher values of $\alpha$ - the distribution is skewed to the right (note that the case of a skew to the left can be analyzed in a similar manner). The representative policy-maker will again choose the mean (in our example, $\alpha=0.75$ ). Given the shown distribution, the monetary policy committee under majority voting would also choose a higher value, i.e., the median $(\alpha=0.78)^{12}$. By contrast, under the unanimity rule, the committee would confirm the prior ( $\alpha=0.5$ ). Whether the committee would choose a higher value $\alpha$ under qualified majority voting depends on the quorum.

What does this imply for the hedging behavior of policy-makers in our thought experiment? First, as shown in Figure 2 (RHS), under the unanimity rule

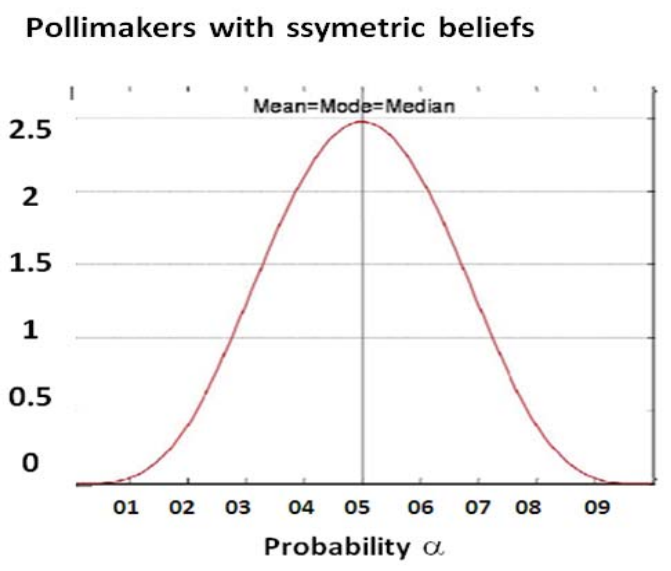

and, possibly, under a qualified majority voting rule, the monetary policy committee would have a tendency to confirm the initial value $\alpha$ (one may characterize this as a "non-activist" approach to risk management). Because the committee as a whole is reluctant to agree on the validity of a different risk scenario, its ability to buy sufficient insurance against the risk of policy error depends on whether the starting value for $\alpha$ is, initially, chosen high enough, so as to encompass situations with higher risks. Second, the representative policy-maker and committees with majority voting are more likely to agree on a new probability $\alpha$, and thereby would more flexibly shift between buying more and less insurance (one may characterize this as an "activist" approach to risk management). The committee's ability to properly insure against the risk of policy error now depends on whether a majority of committee members succeeds in correctly anticipating the direction of a future shock.

\section{Pollimakers with assymetric beliefs}

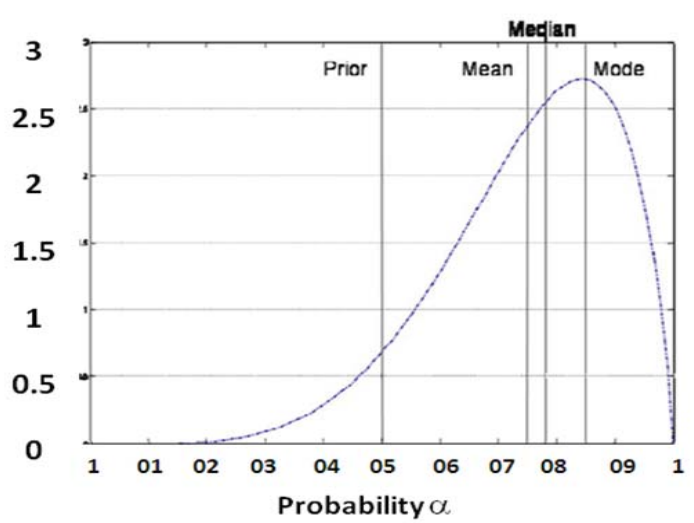

Fig. 2. Policy-makers' beliefs on the probability $\alpha$

\section{Conclusions}

The classical risk management approach to monetary policy has known limitations. One is the neglect of search costs. Our model includes search costs and suggests that, in the presence of Knightian uncertainty, policy-makers could reduce the risk of a policy error by increasing their investment in information search, even though information gathering is costly. We show that it would be optimal for expected utilitymaximizing policy-makers to fully insure against the expected loss from a potential policy error. These considerations are based on the availability of a technology that allows policy-makers to hedge against the risk of policy error. In our model, policy-makers' information search is a means to hedge against the negative consequences of adverse shocks. In practice, several factors prevent a monetary policy committee from sufficiently hedging against the risk of a policy error. These factors include the voting system and heterogeneous skills.

\section{References}

1. Adam, K. and R. Billi. (2006). Monetary Conservatism and Fiscal Policy, Working Paper Series, No 663, ECB, Frankfurt am Main, July.

2. Arnott, R. and J. Stiglitz. (1988). The Basic Analytics of Moral Hazard, Scandinavian Journal of Economics, 90 (3), pp. 383-413.

3. Austen-Smith, D. and J. Banks. (1996). Information, Aggregation, Rationality and the Condorcet Jury Theorem, American Political Economy Review, 90, pp. 34-45.

\footnotetext{
${ }^{12}$ Note that the mean exceeds the median may not be observed for all distributions. It is for the purpose of illustration. For certain distribution, a skew to the right may imply that the median exceeds the mean.
} 
4. Bank for International Settlements. (2009). Issues in the Governance of Central Banks, Report of the BIS Central Bank Governance Group, Basle, May.

5. Berk, J. and B. Bierut. (2009). Monetary Policy Committees - Meetings and Outcomes, Working Paper Series, No. 1070, ECB, Frankfurt am Main, July.

6. Berk, J. and B. Bierut. (2005). Communication in Monetary Policy Committees, DNB Working Paper Series, No 59, De Nederlandsche Bank, Amsterdam.

7. Bernanke, B. (2010). On the Inplications of the Financial Crisis for Economics. Speech delivered at a conference co-sponsored by the Bendheim Center for Finance and the Center for Ecomomic Policy Studies, Princeton, New Yersy, on 24 September, 2010.

8. Blinder, A. (2004). The Quiet Revolution: Central Banking Goes Modern. Yale University Press, New Haven.

9. Brainard, W. (1967). Uncertainty and the Effectiveness of Policy, American Economic Review, Papers and Proceedings, 57 (2), pp. 411-425.

10. European Central Bank. (2008). Short-term forecasts of economic activity in the euro area, Monthly Bulletin, ECB, April.

11. European Central Bank. (2001). Monetary policy-making under uncertainty, Monthly Bulletin, ECB, January.

12. Fama, E. (1970). Efficient Capital Markets: A Review of Theory and Empirical Work, Journal of Finance, 25 , pp. 383-417.

13. Gerlach-Kristen, P. (2004). Monetary policy committees and interest rate setting, European Economic Review, 50, pp. 487-507.

14. Gerling, K., H.P. Grüner, A. Kiel and E. Schulte. (2005). Information acquisition and decision making in committees: A survey, European Journal of Political Economy, 21 (3), pp. 563-597.

15. Greenspan, A. (2004). Risk and Uncertainty in Monetary Policy, American Economic Review, 94 (2), pp. 33-40.

16. Kenny, G. and J. Morgan. (2011). Some lessons from the financial crisis for the economic analysis, Occasional Paper Serie, No 130, ECB, Frankfurt am Main, November.

17. Kilian, L. and S. Manganelli. (2008). The Central Banker as a Risk Manager: Estimating the Federal Reserve's Preferences under Greenspan, Journal of Money, Credit and Banking, 40, pp. 1103-1129.

18. Krugman, P. (1998). It's Baaack: Japan's Slump and the Return of the Liquidity Trap, Brookings Papers on Economic Activity, 29 (2), pp. 137-206.

19. Smidkova, K. (2003). Methods Available to Monetary Policy Makers to Deal with Uncertainty, paper prepared for the conference, Forecasting in a Central Bank, Bank of England, London, August.

20. Taleb, N. (2007). Black Swans and the Domains of Statistics, The American Statistician, 61 (3), pp. 1-3.

21. Tideman, N. (2006). Collective decisions and voting; the potential for public choice. Ashgate Publishing Ltd., Aldershot.

22. Varian, H. (1992). Microeconomic Analysis, third edition. Norton \& Company, New York.

23. Wieland, V. (2006). Monetary Policy and Uncertainty about the Natural Unemployment Rate: Brainard-Style Conservatism versus Experimental Activism, Advances in Macroeconomics, 6 (1), pp. 1-34. 